\title{
Mechanical engineering and social technology: structural design and building of a glass grinder for a recyclable materials collectors' association
}

\author{
Projeto estrutural de uma moedora de vidro destinada à Associação de \\ Catadores de Material Reciclável de São João del-Rei
}

\author{
João Gabriel da Cruz Passosl \\ Ana Flávia Oliveira AlencarlI \\ Mariana dos Santos BarrosollI \\ Nathália Caroline Spineli Forzan SilvalV \\ Valdecy Rodrigo do Nascimentov \\ Leandro Reis MunizVI \\ Artur Mariano de Sousa MalafaiaVII
}

\begin{abstract}
Recycling has an important role on the reduction of environmental impacts caused by production via raw materials. Due to its importance to the recycling process, this study aimed to help the Recyclable Material Collectors' Association of the city of São João del-Rei, Minas Gerais, proposing a glass grinder design. The viability of the machine was evaluated, and the components were sized. After these steps, a structural design was made, using concepts related to Materials Selection, Mechanics of Materials, Mechanical Design, Machine Design, Manufacturing Processes and Vibrations. Simultaneously, the process of building the structure was conducted, concerning the search for resources, adapting the theoretical design when needed, and also the documentation and training of the future users. Finally, the project showed satisfactory characteristics considering the primary objectives, and a high reproducibility. It has the potential to present positive social effects and reduce the environmental impact of glass waste. The process by which it was conducted was very

IMechanical Engineer, Department of Mechanical Engineering, Federal University of São João del-Rei, São João del-Rei, MG, Brazil Email: joaoglancetti@gmail.com

II Mechanical Engineering Student, Department of Mechanical Engineering, Federal University of São João delRei, São João del-Rei, MG, Brazil Email: flavinhagherardi@hotmail.com

III Mechanical Engineering Student, Department of Mechanical Engineering, Federal University of São João delRei, São João del-Rei, MG, Brazil Email: marianabarroso308@gmail.com

IV Mechanical Engineering Student, Department of Mechanical Engineering, Federal University of São João delRei, São João del-Rei, MG, Brazil Email: nathaliacspineli@gmail.com

$\checkmark$ Mechanical Engineer, Department of Mechanical Engineering, Federal University of São João del-Rei, São João del-Rei, MG, Brazil Email: valdecyn@yahoo.com.br

VI Professor Doctor at Department of Mechanical Engineering, Federal University of São João del-Rei, São João del-Rei, MG, Brazil Email: leandro.reis@ufsj.edu.br

VIIProfessor Doctor at Department of Mechanical Engineering, Federal University of São João del-Rei, São João del-Rei, MG, Brazil Email: arturmalafaia@ufsj.edu.br
\end{abstract}


simple and efficient, especially regarding the use of basic concepts and simple mathematical relations instead of complex analyses, favoring its application in other low-resource projects aiming mainly for a high safety factor.

Keywords: Glass, Recycling, Social Technology, Structural Design, Hammer Mill.

\section{Resumo}

A reciclagem possui papel importante na redução de impactos ambientais causados pela fabricação de produtos a partir de matérias primas. Considerando seu importante papel no ciclo de reciclagem, buscou-se auxiliar a Associação de Catadores de Material Reciclável de São João del-Rei, Minas Gerais, com o projeto de uma moedora de vidro. A viabilidade do projeto foi avaliada, e alguns elementos foram dimensionados. A seguir, o projeto estrutural foi feito, com o uso de conceitos relacionados à seleção de materiais, mecânica dos materiais, projeto mecânico e de máquinas, processos de fabricação e vibrações. Simultaneamente, o processo de construção da estrutura foi conduzido, envolvendo a busca por recursos, a adaptação do design teórico quando necessário e a documentação e treinamento de futuros usuários. Ao fim, o projeto se mostrou satisfatório no referente ao funcionamento e reprodutibilidade. Por fim, ele possui potencial para causar efeitos positivos no âmbito social e ambiental, ao reduzir o impacto de resíduos de vidro deixados no ambiente. Além disso, o processo desenvolvido foi simples e eficiente, principalmente por seu uso de conceitos básicos e relações matemáticas simples, favorecendo sua possível aplicação em outros projetos com pouco recursos buscando alto fator de confiança.

Palavras-chave: Vidro, Reciclagem, Tecnologia Social, Projeto Estrutural, Moedora de Martelos. 


\section{Introduction}

Structural design is an area of mechanical engineering focused on the development of structures. These structures take a wide variety of forms (buildings, bridges, machines), and each of those brings a series of particular problems to be solved by the designer. The process is usually iterative, based on the revision of previous steps when a certain project parameter cannot be met in the way its original version intended. This is a fundamental concept, as it makes it hard to treat the process (and the problems) as various independent steps (NORTON, 2013; SMITH; EPPINGER, 1997).

According to Norton (2013), structural design applied to machines is different from those of static structures, and usually involves dynamic considerations. However, a static condition could be applied to machine design when the magnitude of its movements is negligible. This indicates that searching for fundamental rules in structural design is difficult. Therefore, the author shows that even if the principles and methods of mechanical design are very similar among different projects, an evaluation of the specific structure being developed is important and it starts with a comprehension of its main function.

Glass grinders are machines used to comminute large objects of glass into manageable pieces. Grinders can have a large array of working principles; for glass grinders, one of the most used construction forms is the hammer mill. Hammer mills are simple machines, consisting on a rigid structure with an entrance and an exit, usually covered by a screen which controls the size of expelled particles. The main part of the structure contains the shaft and hammers, responsible for comminuting the material fed into the machine (BOCHAT; WESOLOWSKI; ZASTEMPOWSKI, 2015). The hammers are usually thick and elongated pieces of hardened steel, they are coupled with the shaft, turning along with it. The chamber housing these hammers was shaped such that any material entering it collides with these hammers at high velocity. These collisions are responsible for comminuting the 
material. Although simple, it was previously observed that controlling operational parameters is fundamental in the design of these machines, having an influence of up to 400\% on grinding efficiency (YANCEY; WRIGHT; WESTOVER, 2013). These machines can be used on the preparation of glass for recycling purposes, as shown by a previous study (FERRARI et al., 2018).

Glass is a recyclable material, and its recycling brings a series of positive environmental impacts, when compared with its production from raw materials, such as a reduction of $32 \%$ of the energy used, $20 \%$ of the pollution generated, $80 \%$ of mining waste generated and $50 \%$ of water used (MEDINA, 2007). However, the material is less attractive to recyclable materials collectors than plastic or paper, for example. According to a previous study, this is due to a low sale value, combined with the hazards associated with the handling and preparation of the material, as well as its high specific weight (TORRES; GONÇALVESDIAS, 2018). However, the Recyclable Materials Collectors' Association of São João del-Rei (ASCAS) showed interest in collecting and recycling this material, if they had a machine capable of making the process safer and more efficient (PASSOS et al., 2017). The association was established in 2003, and has a long-standing history of cooperation with the Federal University of São João del-Rei (UFSJ) (ABREU; BARBOSA, 2007). Considering the already established link between university and collectors, the authors proposed to design and build a hammer mill grinder for the comminution of glass bottles. The process started with the development of the grinding system, concerning the shaft, hammers, motor and connecting elements (PASSOS et al., 2017). It is comprised by four hammers equally spaced along an axis. This project is based on the concept of Social Technology, a series of transformative techniques and methodologies developed in a joint effort between holders of technical knowledge, such as college students and teachers, and the external community (MIRANDA; LOPEZ; COUTO SOARES, 2011).

The next step of the project, described in this paper, was the development and building of the machine's physical structure. To design this structure, the authors evaluated a series of machine design concepts, seeking to apply the ones deemed relevant to the project. The design should also be simple enough to be understood and replicated. The machine has a potentially positive effect on the lives of recyclable material collectors; it can 
also help ease the environmental impact of glass waste. Therefore, it is interesting to not develop it as a single project, but as part of an ongoing effort to equip associations like ASCAS with proper machinery. Therefore, the main objective of this study was to evaluate the possibility of building an adequate structure using simple machine design concepts, and determining which ones are relevant to the design of glass grinders. The machine should be cheap, easily maintained and simple to operate.

\section{Methodology}

\subsection{Defining the structure's shape}

To start designing the machine it was necessary to define its shape. The main factors considered in this process were the maximum and minimum height, feeding capacity, the space where the machine would be kept, risk factors and how easy the machine was to handle. To this end, the authors used the security standards defined especially by NR 12 , and information obtained in talks with the collectors. The drawings presented in this paper were made with the software Autodesk Inventor 2019. The software was also used for calculations described in section 2.4. Its availability motivated the group choice. Although a CAD software made the design process easier, the calculations and drawings could be made with cheaper or free software, or even by hand. The drawings used to build this machine were also made available to interested associations. Having defined the structure's shape, the group had to select the materials which would compose it.

\subsection{Materials selection}

The main goal was to find a material which could be obtained in the necessary quantity via donations or for a low price. Also, factors specific to the design of glass grinders were considered, like the need for certain parts be resistant to abrasion, as well as the mechanical and vibrational resistance of the system as a whole. The choice process would be initially guided by one described in the literature (ASHBY, 2005), consisting on separating these parameters in classes: choice restrictions, primary design necessities, main functions 
which have to be verified and free choices, which allow for changes in the project, if needed. Knowing the material which would be used in the machine's fabrication, the fabrication processes needed to build it were to be defined next.

\subsection{Fabrication processes}

Firstly, an evaluation of which processes were adequate, considering the chosen material, was made. The cutting and assembling techniques were of special interest, and defining the sheets' thicknesses was an important decision in this stage. After that, the group defined the best course of action to conduct these processes. In this stage, it was important to separate the structure in a group of sheets which would be later joined. This helped plan the cutting process and also avoided waste of material.

\subsection{Structural stability}

The previous steps defined the weight of the structure, allowing the evaluation of its stability. Since the shaft's rotation is considerably high (1750 RPM), and constant impacts with the glass are expected, the vibration developed could be an important guiding parameter for the design. This phenomenon, however, could be counteracted after the machine was already built, via the introduction of dampeners.

Furthermore, the structure's stability is also related to its weight distribution, and this parameter could not be changed afterwards. The process of asserting this stability was related mainly to the position of the center of mass and its impact on the structure's tipping point when combined with externally applied forces. The type of fasteners used on the parts not permanently joined was also chosen and the elements were sized.

\subsection{Structural strength}

This process consisted on evaluating the mechanical integrity of the structure. First, an analysis of mechanical stresses was made. The goal was to define the dimensions needed so that the machine was stable. Concepts related to beam failure and buckling were used.

The base's feet were modeled as L-shaped beams, corresponding to the material received via donations. The calculations, therefore, had the aim of determining if the received 
material could be safely used. Mathematical relationships found in previous works were used (HIBBELER, 2004).

\subsection{Other considerations}

The structure had to be implemented with accessory components responsible for guaranteeing the safety and functionality of the machine. First of those is a form of protection in the feeding channel, avoiding the return of potentially harmful glass shards at high speeds. This protection had to be designed in a way that no glass could return, and the feeding process was not hindered.

The exit channel also had to be considered. It is commonplace in hammer mill grinders the presence of screens in a large array of shapes and sizes (YANCEY; WRIGHT; WESTOVER, 2013). Screens keep the material inside the grinding chamber until the particles are small enough to pass through it. To define the desired granulometry of the ground glass, contact with potential buyers was made. Simultaneously, the screen design progressed with evaluation of potential materials to be used in its construction and how it should be constructed. Another consideration concerned the sealing of the exit channel. Together with the rougher ground glass, over-ground fine particulate could leave this channel, and stay in suspension; constantly breathing it would be a health hazard.

Finally, assembling and disassembling processes had to be evaluated, taking into account routine maintenances; mainly, the machine should have no inaccessible components. The group wrote a comprehensive user's guide, which the collectors will use.

\section{Results and Discussions}

\subsection{Defining the structure's shape}

The first draft of the machine's structure (Figure 1) was based on common hammer mills. An inclined channel (B) serves as a feeding tunnel, leading to an enclosed chamber (F), housing the shaft and hammers, moved by an electric motor, placed at C. A base (D) shaped as a common table with four legs (E) supports the machine's body. The "chimney" shaped 
extension to the feeding tube (A) was chosen due to the possibility of glass shards hitting the hammers and returning at high velocity. The bend of the extension and its considerable length ensue that these shards collide with the inner walls of the structure, reducing their exit velocity.

Figure 1 - Isometric view of the structure and its main components: feeding chute extension (A); feeding chute (B); space for motor placement $(C)$; base (D); legs $(E)$, grinding chamber (F).

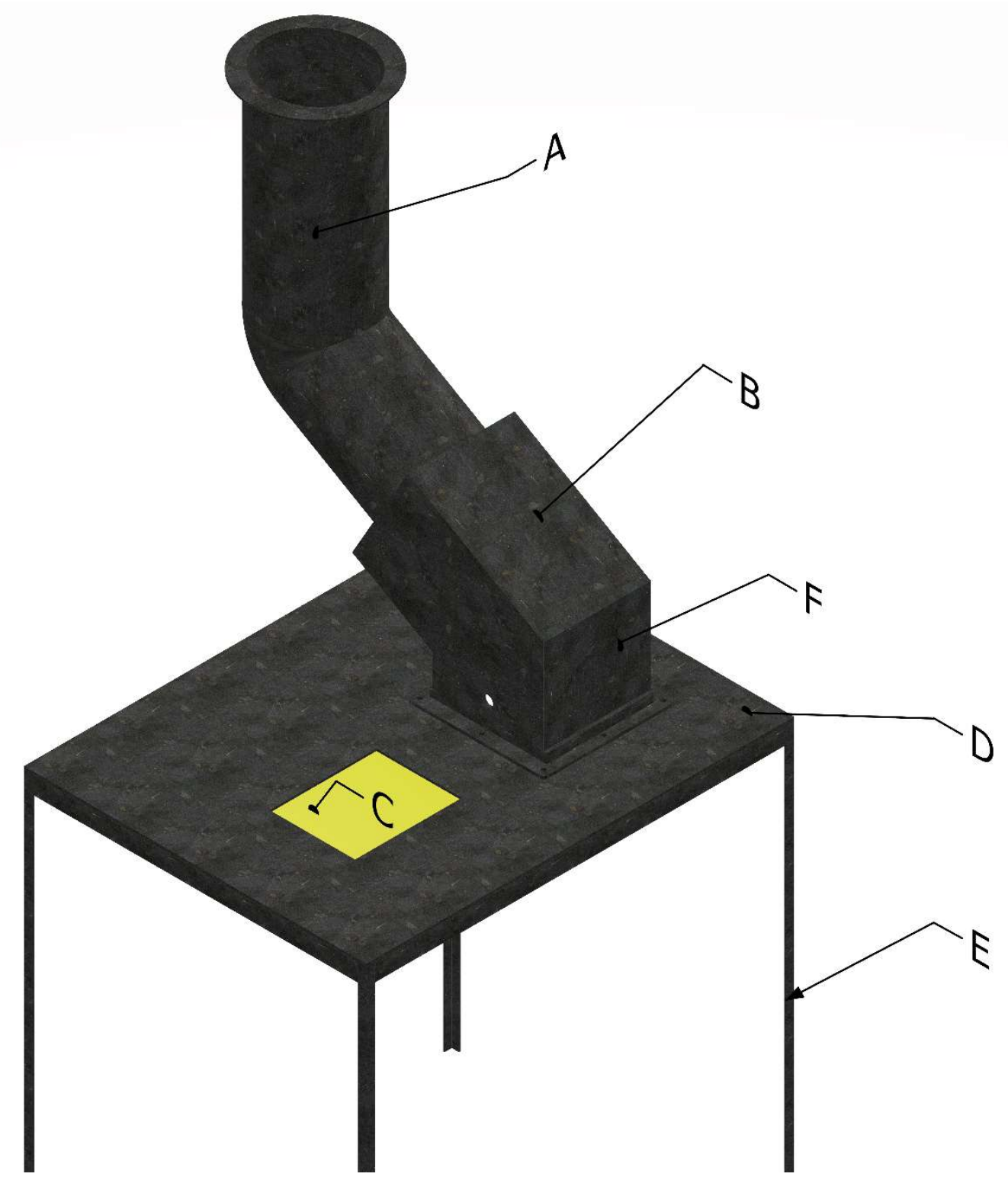

Source: Authors (2020) 
The distance between the top of the machine and the ground was approximately 2 meters, superior to the collectors' average height. This height would lead to an uncomfortable and potentially unhealthy working condition, in which they would have to constantly lift the glass objects overhead. Constant overhead lifting movements are shown to cause physical problems in workers, especially in the shoulders (SOOD et al., 2017). However, since reductions to the machine's size would be irreversible, the dimensions were kept until the first version of the machine was tested; the tests allowed the group to define a better way to make the machine's operation easier. Also, the place where the machine would be put had to be evaluated first, as it could have a bearing on this decision (an elevated operational area in relation to the grinder could compensate for a tall machine). These are further discussed in section 3.7.

The table would measure $800 \times 1000 \mathrm{~mm}$. Total lateral dimensions were approximately $1000 \times 1000 \mathrm{~mm}$, as shown in Figure 2. Visits to the Association showed that it had an adequate space to accommodate the machine; the operator would have ample space to work, and a safety zone could be established around the grinder.

Figure 2 - Lateral dimensions of the machine, considering only the table $(1000 \times 800 \mathrm{~mm})$ and the maximum lengths $(1000 \times 1001 \mathrm{~mm})$.

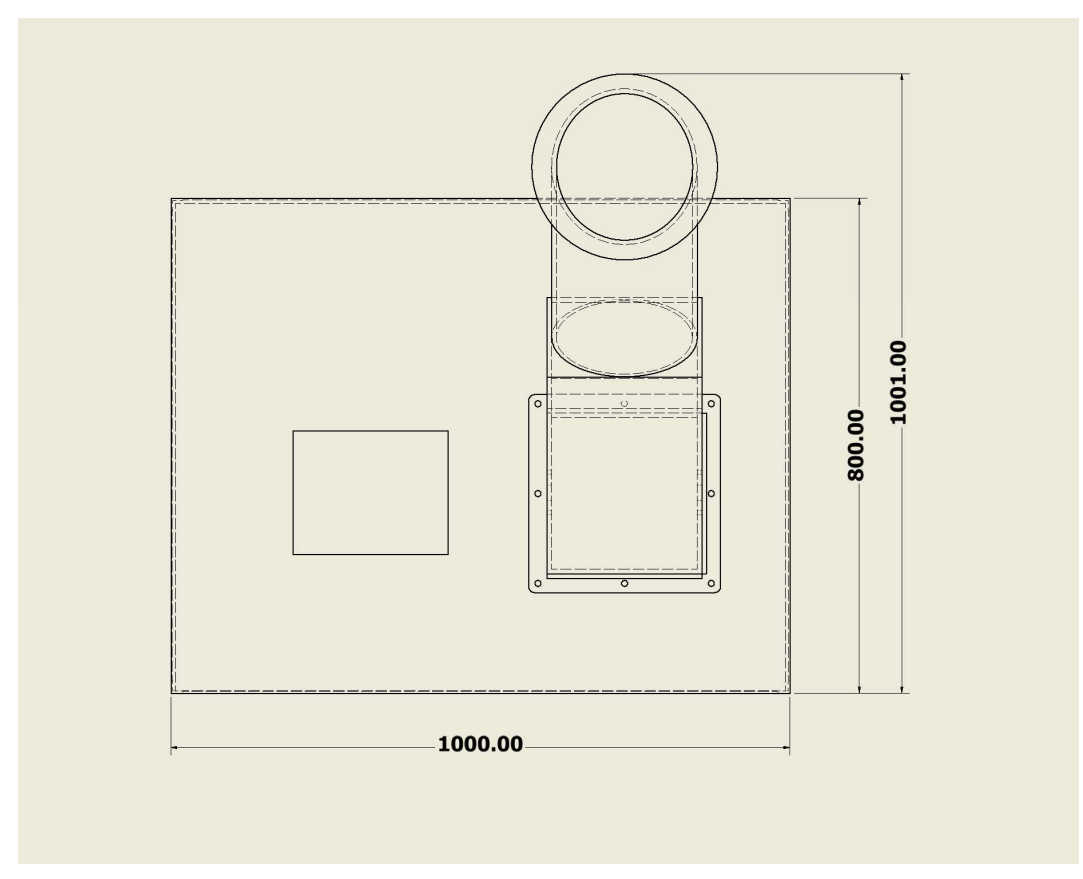


Source: Authors (2020)

This structure would lead to an easily operable machine, with only one entrance and one exit, and no exposed moving parts. The dimensions of the chimney were defined by the availability of a steel structure with the desired shape in the university, given to the group as a donation.

\subsection{Materials Selection}

Hot rolled sheets of medium resistance structural steel were chosen to be used. The material is widely used, having a good mechanical resistance and low cost; it is also weatherresistant, with the proper treatments (BROCKENBROUGH; MERRITT, 1999). Steel sheets are easily found as scrap metal, the material is easy to machine and weld. The same steel was used in every part of the structure, except the chimney. The chimney is made with an uncharacterized type of steel, but since the part was not load bearing, its mechanical properties were of little interest. It was verified only that the material could be welded and painted. Since common steel is prone to oxidation and other forms of corrosion, the structure would be covered with a protective paint, which can be applied or reapplied quickly and cheaply.

The design allowed for the choice of different materials. Stainless steels, for example, have a higher resistance to oxidation and corrosion (and a higher mechanical resistance, depending on the alloy) but are more expensive. Hardened steels are less prone to wear, while also being costlier, and harder to work with, than structural steel (CALLISTER JR; RETHWISCH, 2012). These materials, thus, would be less cost efficient, and most important, less accessible. Analysis of the processes of material selection showed that, for the type of product proposed here, it is best to use a common and reliable material, avoiding unnecessary complexities and costs, even if some properties of the final product, like weight, could be optimized with the use of more sophisticated materials.

Abrasion resistance was a relevant parameter for parts acting directly on the grinding process. The hammers would be exposed to a surface hardening treatment, as they withstand most of the abrasion, according to a previous study (KALLEL et al., 2017). The inner 
walls of the grinding chamber are also exposed to abrasive impacts with glass. To counteract any possible effect of this phenomenon on these walls, an empty space was left inside the grinding chamber, indicated by $A$ in Figure 3 , between the hammers' path and the wall most exposed to impacts. A hardened steel sheet could be fixated in this space if an excessive abrasion of the inner wall was detected.

Figure 3 - Grinding chamber (internal view). The arrow indicates the direction of rotation. A indicates a possible location for the placement of reinforcements.

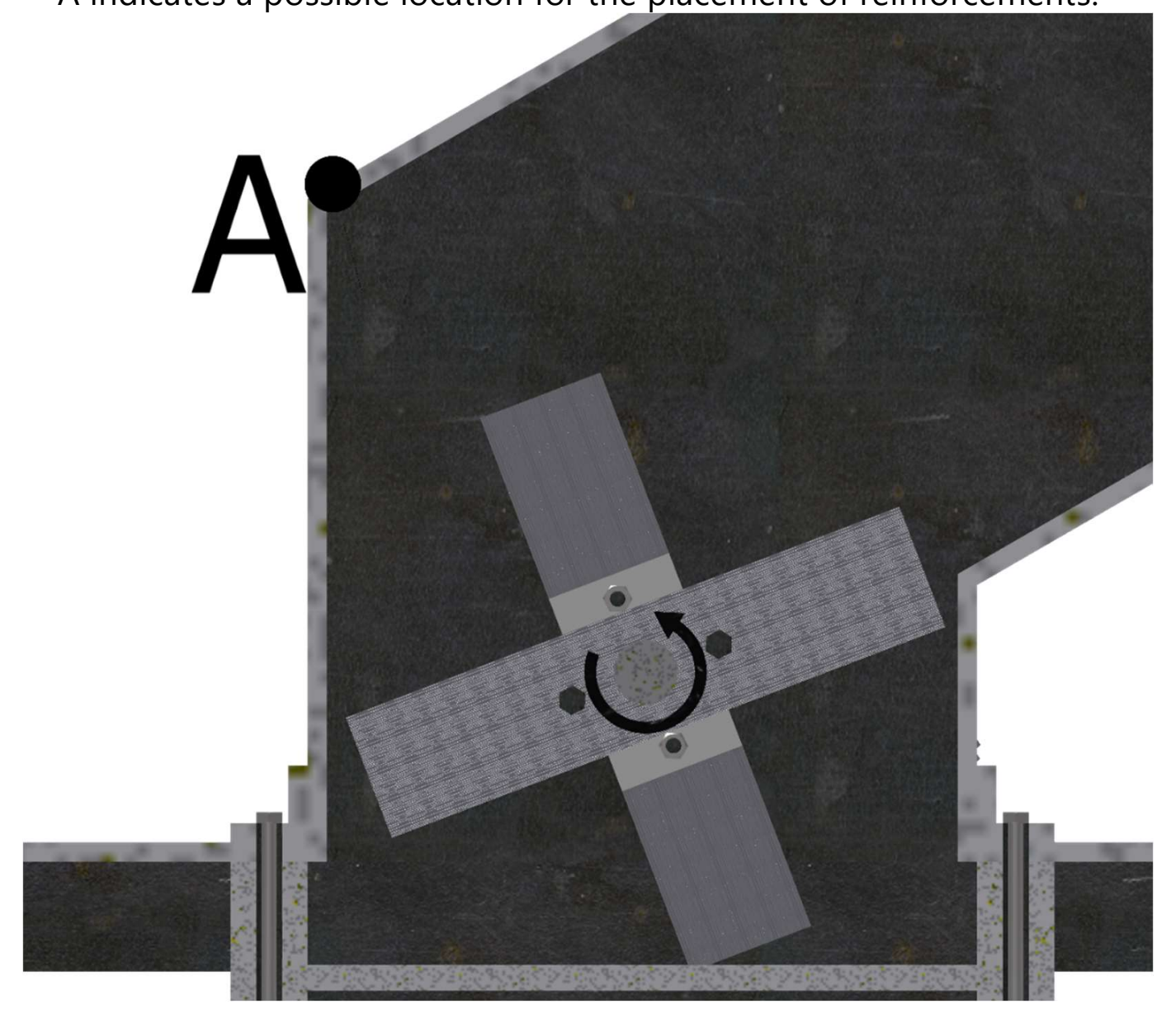

Source: Authors (2020)

Applying mathematical models to properly evaluate the vibration developed would be a complex task, going against the primary goal of developing a simple process. Thus, this 
phenomenon was considered during the testing phase. If substantial vibration was observed, there would be the possibility of adding dampeners.

\subsection{Fabrication Processes}

Figure 4 shows the disposition of plates which compose the machine's body. The steel sheet, from which the plates were cut from, was considerably thick $\left(1 / 4^{\prime \prime}\right)$, as a higher resistance and rigidity compensated the increase in cost. However, this meant that they had to be prepared with oxy-fuel cutting. A lower cost might be achievable opting for the use of a thinner sheet, but the use of thick plates simplified the project. Furthermore, thicker plates are more rigid, avoiding problems with deformation due to stresses.

Figure 3 - Plates to be used for the main body's assembly and corresponding dimensions.

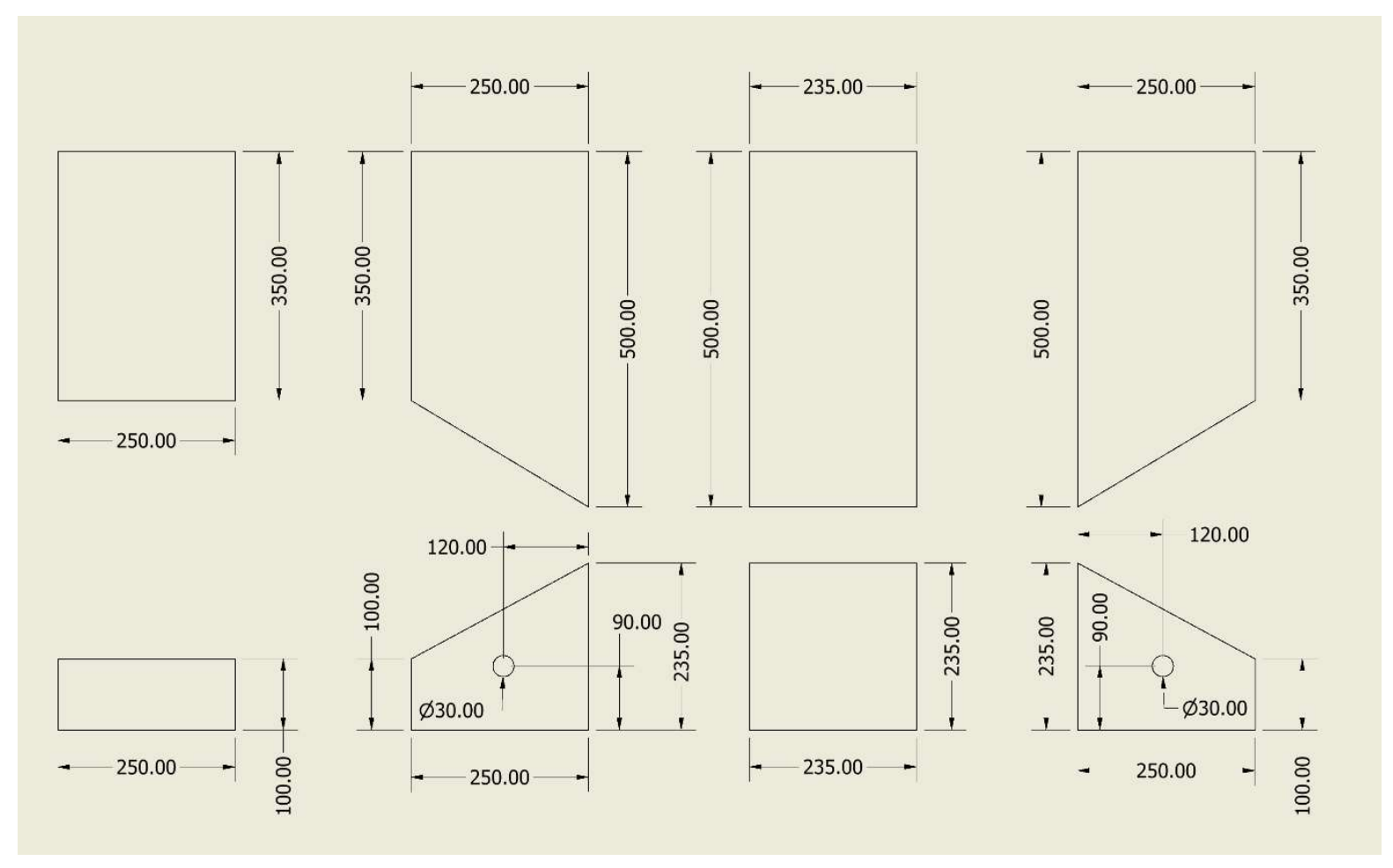

Source: Authors (2020) 
The plates were welded with common $3.25 \mathrm{~mm}$ electrodes. Preparations consisted on cleaning the surfaces which would be joined. Reinforcements would be put in place if needed, strengthening the mechanical resistance of the joint. However, the group was careful to avoid large loads on welded joints, taking into account the stresses generated by the process, which could cause anomalous behaviors responsible for early failures in tensile and fatigue regimes (JEFFUS, 2020). The only welded joint which could be subjected to significant load is the one connecting the feeding chute to its extension, since it was subjected to moment caused by the chimney's weight. However, the large contact area between these two parts allowed for a strong weld, and tests showed no sign of mechanical failure.

\subsection{Structural Strength}

The weight of the structure was calculated with the software Autodesk Inventor, as approximately $120 \mathrm{~kg}$. Elements of the machine which were not part of the main structure, such as the motor, were not considered. This weight can be seen as focused on a hypothetical point, the center of mass. The center of mass of a complex structure which can be divided in parts with homogeneous density is defined by the mathematical relation shown in Equation 1 (BEER; JOHNSTON JR; MAZUREK, 2015).

$$
C M=\frac{\int_{a}^{b} x d x}{\int_{a}^{b} d x}
$$

In which $\mathrm{x}$ is the distance to a reference point. The center of mass (CM) can be used to verify that some design parameters are being met. Figure 5 shows that it was localized between the legs of the table, $300 \mathrm{~mm}$ away from the closest leg. Therefore, the machine was stable-it would not fall over due to its own weight. However, external forces have to be considered. External forces acting at a certain distance from a pivot point, such as one of the table legs, cause moment. Moment is defined as the product between the load applied and the distance between this load and the pivot. A vertical force could tilt the machine only if it was applied outside the area delimited by the four table legs, as any force applied directly 
over the table itself would be counteracted by them, not causing tilting moment. Figure 5 shows the point where a vertical force would cause maximum moment (A). The load would have to be approximately $1,200 \mathrm{~N}$ to destabilize the table. This would be similar to an approximate weight of $120 \mathrm{~kg}$ being applied directly on point A. Therefore, even considering a critical situation in which an operator of average weight holds himself up on point $A$, tipping would not occur. The weight of the glass being fed could also be a source of tipping moment. However, Figure 5 also shows that the volume of the feeding chute localized outside the table (beyond the red line B) is small (approximately $0.022 \mathrm{~m}^{3}$ ). Glass has an average density of $2,500 \mathrm{~kg} / \mathrm{m}^{3}$ (CALLISTER JR; RETHWISCH, 2012) and completely packed glass occupying a volume of $0.022 \mathrm{~m}^{3}$ would only weight $56 \mathrm{~kg}$. This load is much smaller than the one needed to topple the machine. Besides, the feeding chute will never be completely packed with glass, as glass bottles have a large part of their volume consisting of air.

Figure 5 - Center of mass of the structure and point where loads cause maximum moment $(A)$. The red line $B$ indicates the structure's pivot point.

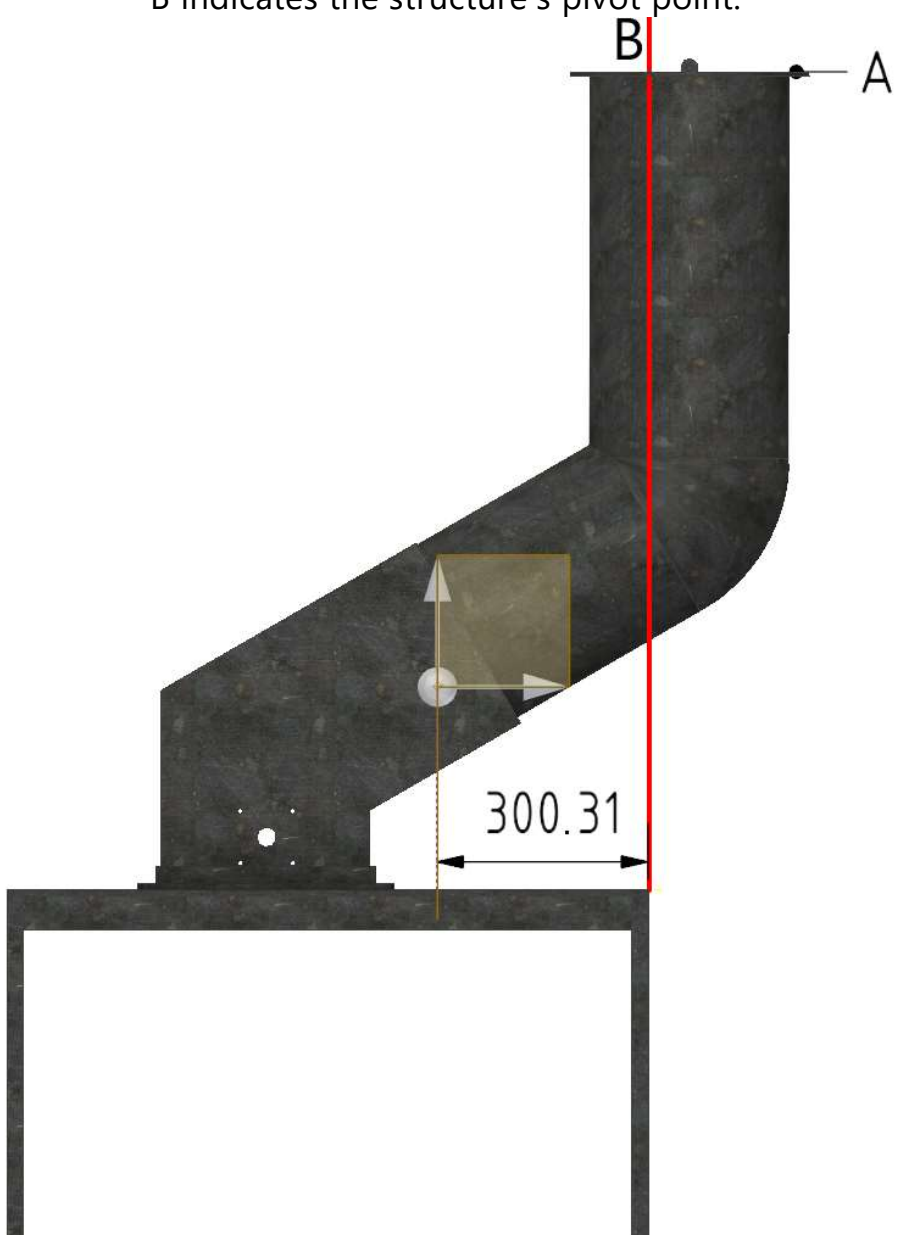


Source: Authors (2020)

Horizonal forces, however, are more critical, due to the machine's considerable height. A horizontal load acting at point B generated a much larger moment than a vertical one. Moment is a product between the load and the perpendicular distance between its point of application and a point of interest (contact between table and ground at line B). While for a vertical force this distance is equal to the horizontal distance between $B$ and $A$, for a horizontal one, its equal to the-much larger-machine's height. Although this kind of push would hardly be observed in normal working conditions, angled loads are expected. Thus, the critical condition-horizontal push-was considered in the calculations. The force needed to tip the table, not considering sliding, is $300 \mathrm{~N}$. It is much smaller than the vertical force, as expected. However, horizontal forces would not be developed by loads caused by feeding or other forms of constantly applied weight, as gravitational forces act vertically. These would only be developed by a momentarily applied load, which would then have to act during a certain amount of for the center of mass of the structure to reach an unstable position. Since the structure is not toppled instantaneously, it is reasonable to assume that the operator would identify an instability and remove it in time. Therefore, it was reasonably assumed that this situation could be avoided by adequate training. Bolting the structure to the ground was, thus, not needed, which is desirable, as the collectors advised the group that the possibility of moving the machine around was advantageous.

To connect the screen, base and body, screws were used, as this section of the machine had to be easily disassembled, giving access to the hammers. A flanged connection was built, and eight screws could be used to connect these parts. Their position is shown in Figure 6. The idea, however, was to use only four screws (at the positions marked in black), easing the disassembling process. 


\section{(Continue...)}

Figure 6 - Upper view of the connection between grinding chamber and table. Positions where screws were placed are highlighted in black. Positions highlighted in gray correspond to places where reinforcement screws can be put.

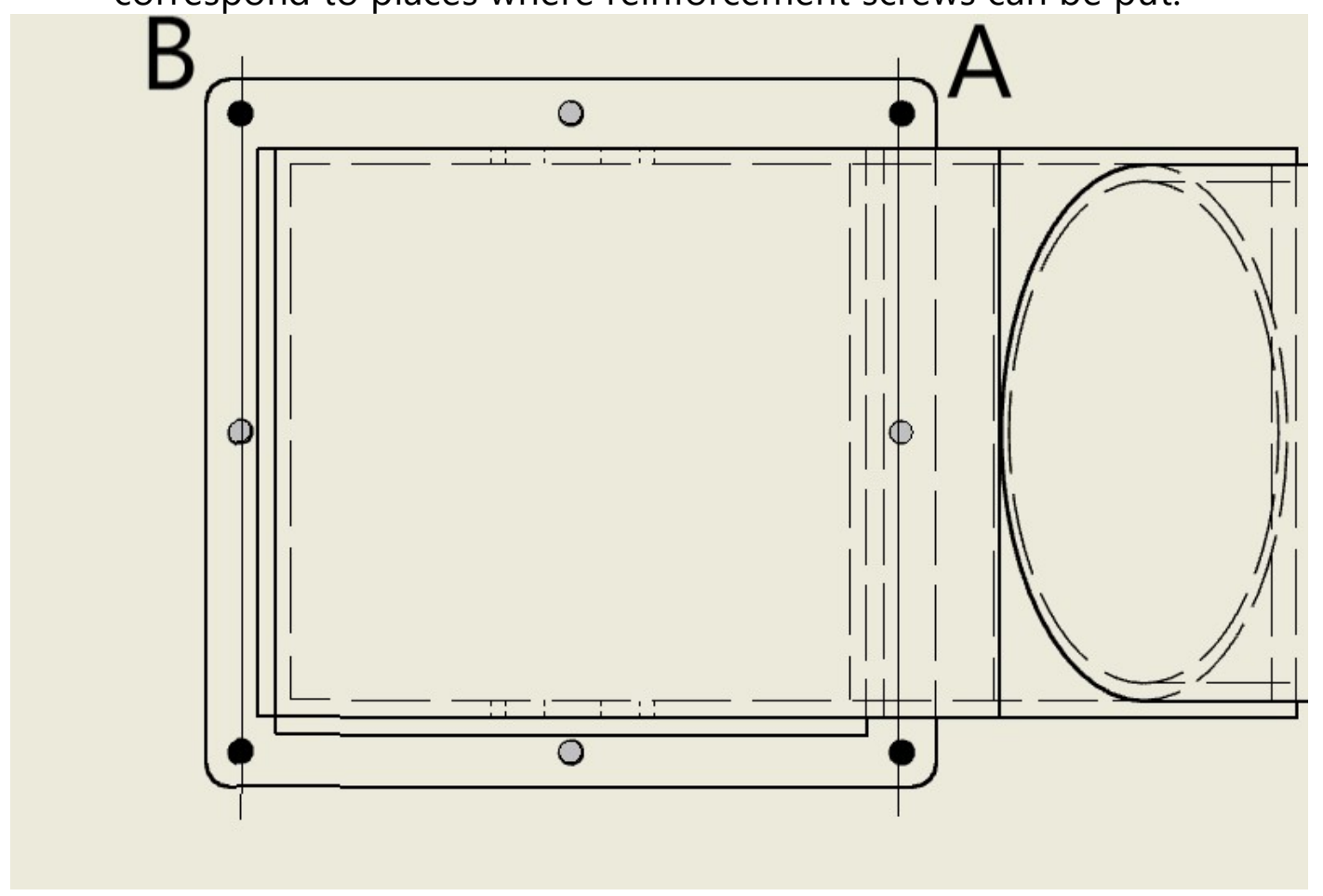

Source: Authors (2020)

This joint was subjected only to vibration and a load caused by the reaction to the moment created by the feeding chute on the flange. This load acts only at the screws located in line B at Figure 6. Figure 7 shows a side view of the machine, A and B correspond lines A and B from Figure 6, respectively. The positions of the bolts are shown marked in black. The screws in line A are at the pivot point, the point which would be the center of rotation of the chute in case its weight (shown W, in Figure 7, acting at the chute's center of gravity) was enough to lead the screws in B to failure. Thus, they cannot create counter moment, acting as non-load bearing fasteners. 
(Continue...)

Figure 7 - Lateral view showing the region in which bolts could bear considerable load (B) and serve only as fasteners (A). The weight of the feeding chute (W) is shown applied at its center of mass.

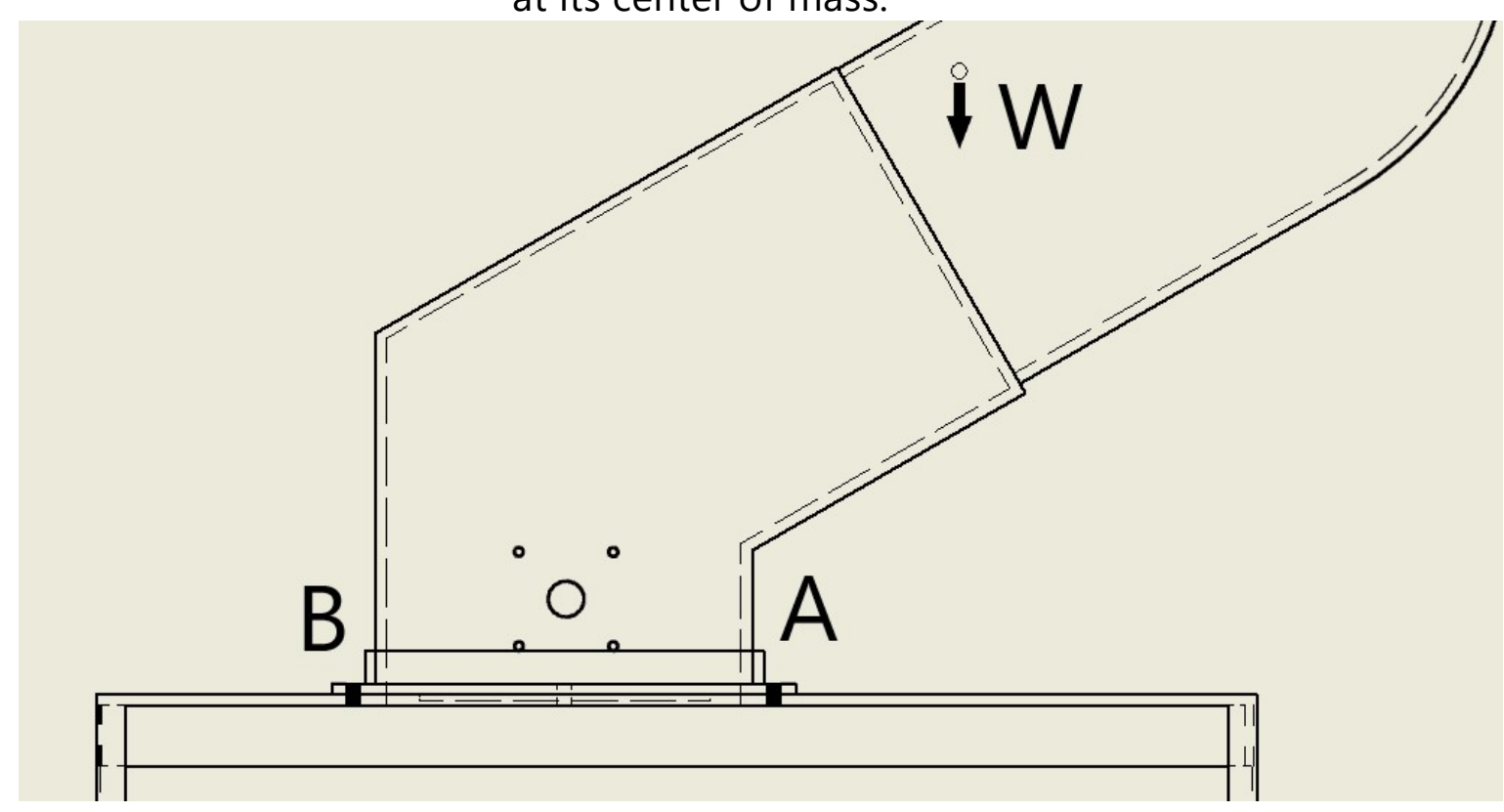

Source: Authors (2020)

Effects due to fatigue were not evaluated, since the forces acting on the dynamic elements (the hammers and shaft) are small compared to the static load. Thus, the amplitude of the combined load was small, defining a system which would fail after a high number of cycles (PAIK, 2018), and a static failure was of higher probability. This static load creates a tensile stress on each screw calculated by Equation 2 .

$$
\sigma_{a d m}=\frac{F}{A}
$$


In which $\sigma_{a d m}$ is the admissible stress, which, considering grade 4.6 bolts, is equal to $225 \mathrm{MPa}$. $\mathrm{F}$ is the acting load and $\mathrm{A}$ is the area under stress. The group desired to use screws with a diameter of $10 \mathrm{~mm}$ (M10 bolts), the same dimensions and model of the fasteners connecting the hammers to the shaft, sized in a previous paper (YANCEY; WRIGHT; WESTOVER, 2013). The option to use screws of the same diameter in every part of the machine was made considering the advantages of standardization (JAKOBS, 2019). Standardizing the screws would make future replacements of parts easier and increase efficiency during maintenance procedures. Equation 2 shows that a bolt with a diameter of $10 \mathrm{~mm}$ could bear a vertical load of $720.55 \mathrm{~kg}$, applying a safety factor of 2.5 recommended by previous works (JUVINALL; MARSHEK, 2011). Therefore, two screws could hold a weight $1,441.09 \mathrm{~kg}$. Since the chute weights approximately $75 \mathrm{~kg}$, it would have to act at a distance of over 19 meters to cause a critical moment. The screws were, in fact, oversized. Thus, only four screws were used, with the design allowing for the use of eight, in case indicatives of premature mechanical failure were observed. Also, due to geometrical constraints, their length was $50 \mathrm{~mm}$.

\subsection{Structural support}

The machine's weight (120 kgf) is naturally distributed along the four legs of the table. It would be possible to find what portion of this load is each leg bearing. Due to the machine's low weight and the option for reliability over optimization, however, the weight was applied over a single leg during theoretical analysis. The buckling analysis was conducted with the use of Equation 3 (HIBBELER, 2004).

$$
P_{c r}=\frac{\pi^{2} E I}{L^{2}}
$$

In which $\boldsymbol{P}_{\boldsymbol{c} r}$ is the critical load needed to cause buckling failure. $L$ is the beam's effective length, $E$ is the modulus of elasticity of the material (equal to $200 \mathrm{GPa}$ for steels) and I the moment of inertia of the profile, found in Appendix B of (HIBBELER, 2004), corresponding to a L-beam (Angle beam) of equal sizes $(51 \mathrm{~mm}$ ) and a thickness of $3.2 \mathrm{~mm}$ 
(L51 $551 \times 3.2)$. The effective length is equal to the beam's length multiplied by a constant $K$ related to the way the beam's extremities are fixated. It is equal to 0.5 for beams embedded in both extremities, therefore, $L$ was equal to $500 \mathrm{~mm}$. With these values, $\boldsymbol{P}_{\boldsymbol{c r}}$ was equal to $631654 \mathrm{~N}$, which is much higher than the machine's weight (1200 N).

The stress regime on the legs was considered pure compression, calculated with equation 2. As with the moment of inertia, area under tension was taken from (HIBBELER, 2004). A stress of approximately $5 \mathrm{MPa}$ was developed, which was much lower than common values of admissible stresses for steels (HIBBELER, 2004). Finite element analysis could be used to obtain a more precise value; however, this analysis would require tools which might be unavailable to groups interested in applying the method presented here to develop similar machines. Also, the real stress value, even if increased by tensile stresses and stress concentrations, would still be divided between four beams. Thus, even thought was possible to build a safe project without the need of complex analyses, the values obtained were imprecise and should not be used for optimization.

\subsection{Other considerations}

To seal the feeding chute against returning pieces of glass, a steel lid was put in place, as shown in Figure 8. It opens by turning against the axis A marked in blue when a small pressure is applied in region $B$. This movement lowers region $B$, opening the feeding chute. At the other half, a counterweight ( $C$, marked in yellow) is lifted along with the region opposite to region B. Due to its own weight, it closes the lid after the pressure is relieved from B. Thus, the operator pushes the object being fed into the machine, and the lid seals the entrance before it reaches the grinding chamber. The counterweight also slightly surpasses the edge of the entrance, so that it opens only in one direction. The same effect could be obtained with a stopper affixed inside the feeding chute.

Figure 8 - Isometric view of the entrance of the machine's feeding chute, protected by the designed system. The system consists of a lid which turns on an axis (A) when pressed at $B$, it closes with the help of a counterweight $(C)$. 


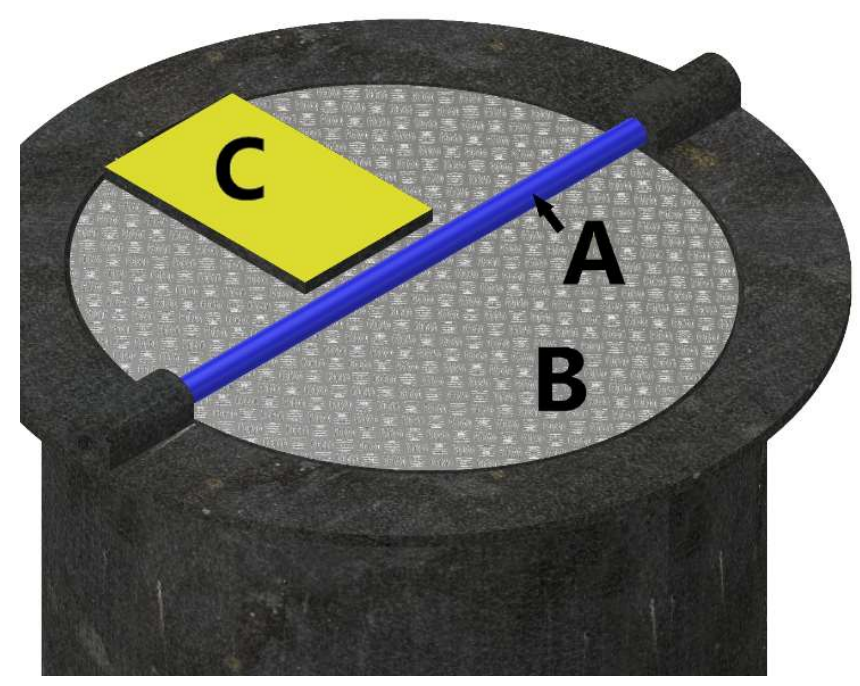

Source: Authors (2020)

A screen, shown in Figure 9, controlled the size of the particles exiting the machine. Also pictured is the previously designed grinding system, with its four hammers equally spaced along an axis connected to the motor. According to potential buyers, the glass should be ground to shards of approximately $70 \mathrm{~mm}$; fine particles are undesirable. Therefore, the screen's function was only to maintain objects inside the machine until a hammer collides with them. Because of that, it was possible to build a cheap screen with scrap metal. Mounted to this screen is a fabric tube (not pictured), thick enough to resist piercing, creating a sealed path between the exit to the container, avoiding contact between operator and glass dust. 
Figure 9 - Isometric view of the screen at the exit of the grinding chamber. The grinding system previously designed is also pictured.

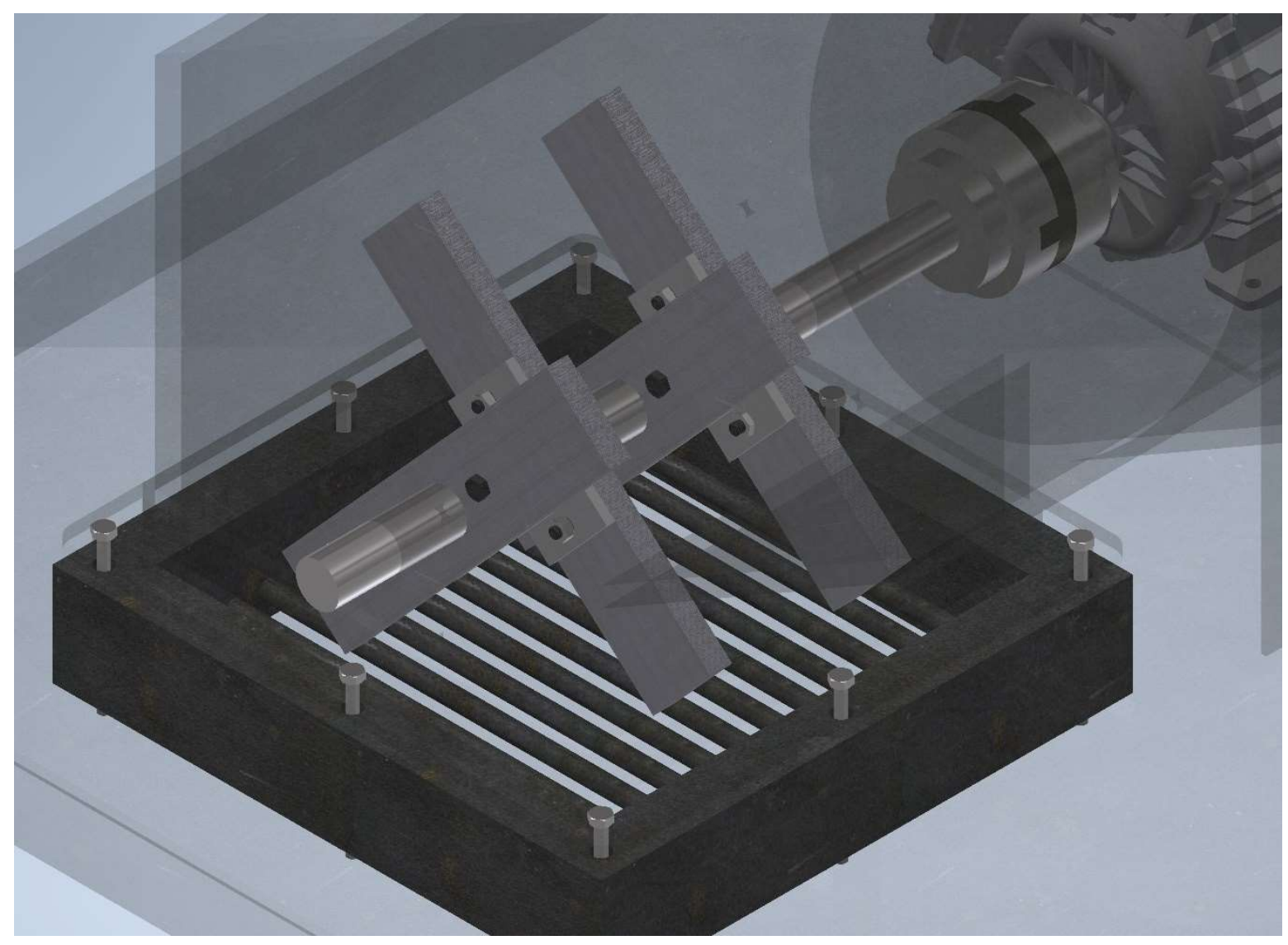

Source: Authors (2020)

The access to moving parts is impossible while the machine is in operation, and the space destined to house the machine is large enough to allow for a safe zone around it. With use of visual aids, a simple manual was produced. Its objective was only to teach the collectors how to operate the machine safely, which protection equipment to use and basic maintenance procedures. More complex maintenances will be left to the university group.

\subsection{Construction}

Most of the building processes were done with use of the university's resources. Some changes were needed due to unforeseen circumstances or changes in the design. First, the 
dimensions of main body (Figure 4) were slightly reduced, since the available material was insufficient; no design parameter was significantly changed due to this alteration.

The project then moved to the testing phase. The grinder was tested inside the university, before being closed off. This test was made to guarantee that it had the desired comminution capability. After some minor adjustments, it was evaluated again before being delivered to the ASCAS. This second test was conducted with the presence of some collectors. During it, they had the opportunity to raise questions and suggest changes. This interaction was essential, considering the Social Technology principles that guided the project, involving the user in the design process. During this test, they raised concerns about the height of the machine, which would make its operation discomforting and unsafe, considering the place where it would be put inside the association's shed.

The machine's height was thus reduced by $500 \mathrm{~mm}$, by shortening the legs of the base. This reduced the space under it, where the recipient for the ground glass would be allocated. It was observed, however, that the space left $(500 \mathrm{~mm})$ was still more than enough to store a significant amount of glass. This change is also beneficial to the structural integrity and stability of the grinder. Shortening the legs increased buckling resistance, and changed the structure's moment of inertia so it was harder to tilt it. Also, a lower height generates a lower moment when a horizontal force is applied, which increases stability.

A last test was made inside the association's base of operations. Figure 10 shows a photo of the final product during this test. It allowed the group to see the machine in action in the place where it would be permanently used. It was observed that the height reduction was sufficient, allowing the collectors to operate the machine and a large amount of glass to accumulate below the base. This test also served as an opportunity to train the collectors and evaluate their satisfaction with the product. After their approval, the machine was permanently given to them. The group still maintained contact with the association, making further adjustments and maintenance processes.

Figure 10 - Final product during its first test inside the ASCAS. A member of the group (left) shows a collector (right) how to operate the machine. 


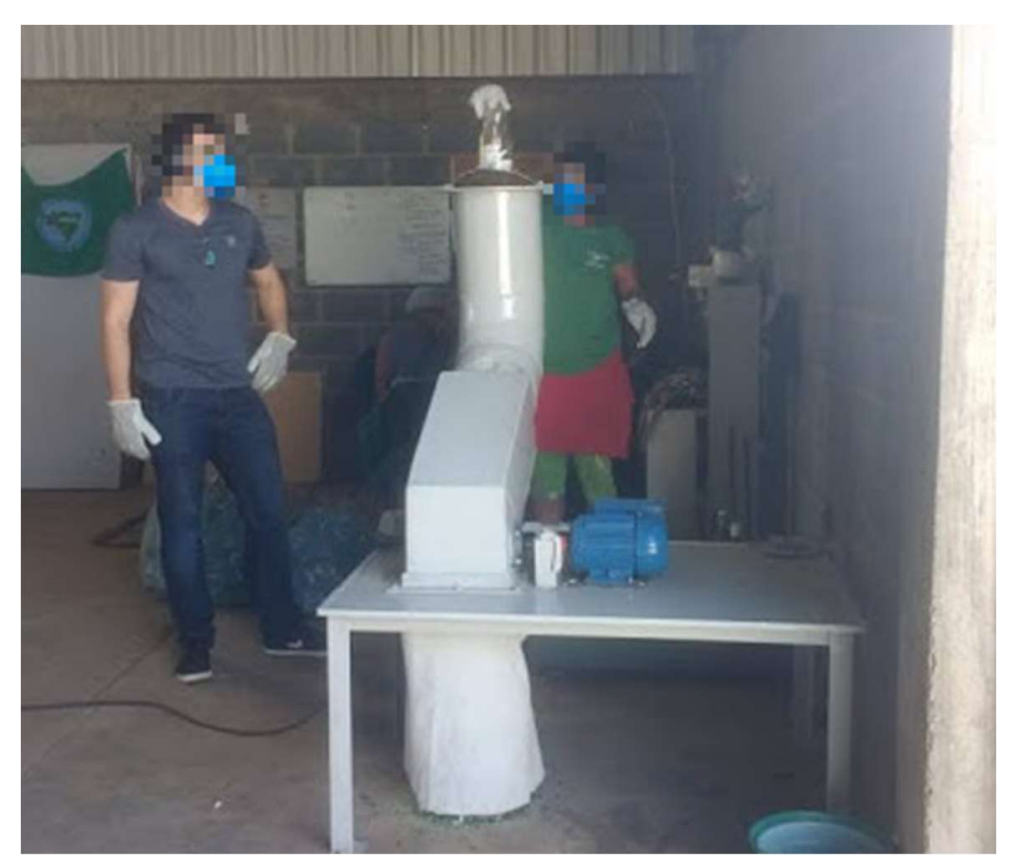

Source: Authors (2019)

\section{Conclusions}

The goal of this project was to develop a process which would be used to design the physical structure of a safe, robust and productive glass grinder. This machine would be evaluated and used by the collectors of the ASCAS to prepare of glass bottles for sale. In order to reach this goal, the group used various principles of machine design and determined how they could be applied in a cheap and safe way. The process was divided in parts: first, the structure's shape was defined; then the materials and fabrication processes used to build were chosen; the integrity of this structure was mathematically evaluated; and, lastly, secondary components were designed and the grinder was built.

It was decided that a hammer mill was the best option. These are simple machines; therefore, the shape of the structure could be defined with the study of similar grinders. Analyses related to materials selection and fabrication processes were almost completely avoided by keeping to a basic construction material (structural steel), which is low cost, reliable, and easily welded. Some considerations regarding structural integrity and stability, such as the possibility of tilting, could be correctly evaluated with mathematical equations. 
Other analyses were, however, less reliable. These were related mainly to loads acting on the machine and the stresses they cause. Since the machine is a complex structure, theses stresses should be determined via computational simulations, which are much more precise. Those, on the other hand, are complex and expensive, and could negatively affect the reproducibility of the design process, which was guided by the principles of Social Technology. Therefore, it was of interest of the group that it could be easily understood and reproduced, even by groups with reduced access to resources and technical knowledge. To avoid using these simulations, the group opted for an oversized design. Since this method still yielded a cheap product, it showed itself to be a valid alternative to computational simulations.

The final processes concerned the description of the evaluation of safety concerns, as well as operational and maintenance processes. Alterations were made to accommodate them, mainly via the introduction of secondary components to the structure, such as the screen. The design process described in this paper was satisfactorily used to build a safe, cheap and productive machine approved by its intended users. The steps described here can help other groups design machines destined to associations which are unable to afford a thorough design process, such as the ASCAS.

\section{Referências}

ABREU, J. C.; BARBOSA, V. R. Monitoramento do processo de gestão da associação dos catadores de materiais recicláveis de São João del-Rei - ASCAS. In: Cooperativismo Popular e Redes Solidárias. [s.l: s.n.]. p. 121-132.

ASHBY, M. F. Materials selection in mechanical design. [s.I.] Elsevier, 2005.

BEER, F. P.; JOHNSTON JR, E. R.; MAZUREK, D. Vector Mechanics for Engineers: Statics. 11. ed. [s.l.] McGrawHill Education, 2015.

BOCHAT, A.; WESOLOWSKI, L.; ZASTEMPOWSKI, M. A Comparative Study of New and Traditional Designs of a Hammer Mill. Transactions of the ASABE, v. 58, n. 3, p. 585-596, 22 jun. 2015. doi:10.13031/trans.58.10691.

BROCKENBROUGH, R. L.; MERRITT, F. S. Structural steel designer's handbook. New York: McGrawHill, 1999. 
CALLISTER JR, W. D.; RETHWISCH, D. G. Fundamentals of materials science and engineering: an integrated approach. [s.I.] John Wiley \& Sons, 2012.

FERRARI, M. V. D. et al. O potencial da cadeia de resíduos de vidro de embalagem no Distrito Federal. Forum Internacional de Resíduos Sólidos-Anais. Anais...2018

HIBBELER, R. C. Statics and mechanics of materials. [s.I.] Pearson Education, 2004.

JAKOBS, K. ICT Standardization. In: Advanced Methodologies and Technologies in Artificial Intelligence, Computer Simulation, and Human-Computer Interaction. [s.l.] IGI Global, 2019. doi:10.4018/978-1-5225-7368-5.ch060. p. 812-825.

JEFFUS, L. Welding: principles and applications. 9th. ed. [s.I.] Cengage Learning, 2020.

JUVINALL, R. C.; MARSHEK, K. M. Fundamentals of Machine Component Design. [s.I.] Wiley, 2011.

KALLEL, M. et al. Hammer premature wear in mineral crushing process. Tribology International, v. 115, p. 493-505, nov. 2017. doi:10.1016/j.triboint.2017.06.025.

MEDINA, M. Waste Picker Cooperatives in Devloping Countries. In: Membership Based Organizations of the Poor. [s.I.] Routledge, 2007. p. 125-141.

MIRANDA, I.; LOPEZ, M.; COUTO SOARES, M. C. Social technology network: paths for sustainability. Innovation and Development, v. 1, n. 1, p. 151-152, 4 abr. 2011. doi:10.1080/2157930X.2011.556470.

NORTON, R. L. Machine design. A integrated approach. [s.l.] Prentice Hall, 2013.

PAIK, J. K. Ultimate limit state analysis and design of plated structures. 2. ed. [s.l.] John Wiley \& Sons, 2018.

PASSOS, J. G. DA C. et al. VALIDAÇÃO E ESPECIFICAÇÃO DOS COMPONENTES DE UMA MÁQUINA DE MOER VIDROS PARA A ASSOCIAÇÃO DE CATADORES DE MATERIAL RECICLÁVEL DE SÃo JOÃo DEL-REI (ASCAS). Anais do VIII COEN. Anais...2017

SMITH, R. P.; EPPINGER, S. D. Identifying Controlling Features of Engineering Design Iteration. Management Science, v. 43, n. 3, p. 276-293, mar. 1997. doi:10.1287/mnsc.43.3.276.

SOOD, D. et al. Predicted endurance times during overhead work: influences of duty cycle and tool mass estimated using perceived discomfort. Ergonomics, v. 60, n. 10, p. 1405-1414, 3 out. 2017. doi:10.1080/00140139.2017.1293850.

TORRES, A. F. R.; GONÇALVES-DIAS, S. L. F. Entendendo a Estrutura da Cadeia Reversa das Garrafas de Vidro em São Paulo. INTERNATIONAL WORKSHOP ADVANCES IN CLEANER PRODUCTION. Anais...2018 
YANCEY, N.; WRIGHT, C. T.; WESTOVER, T. L. Optimizing hammer mill performance through screen selection and hammer design. Biofuels, v. 4, n. 1, p. 85-94, 9 jan. 2013. doi:10.4155/bfs.12.77. 